\title{
Enthalpies of Solution of the Nucleic Acid Bases. 4. Uracil in Water
}

\author{
Marthada V. Kilday \\ Center for Thermodynamics and Molecular Science, National Bureau of Standards, Washington, DC 20234 \\ June 6, 1978
}

\begin{abstract}
An adiabatic solution calorimeter was used to measure enthalpies of solution in water of 7 uracil samples in a concentration range of 3 to $45 \mathrm{mmol} \cdot \mathrm{kg}^{-1}$ and over a temperature range of $298 \mathrm{~K}$ to $325 \mathrm{~K}$. Analytical data for the samples are given.

Our best value for the enthalpy of solution is
\end{abstract}

$$
\Delta H^{\circ}(\infty, 298.15 \mathrm{~K})=(29.3 \pm 1.2) \mathrm{kJ} \cdot \mathrm{mol}^{-1}
$$

and for the change in heat capacity for the reaction with temperature,

$$
\Delta C_{p}{ }^{\circ}=(57 \pm 13) \mathrm{J} \cdot \mathrm{mol}^{-1} \cdot \mathrm{K}^{-1} .
$$

No change in the enthalpy of solution with concentration was found in this range. Values were calculated for the entropy of solution, $\Delta S^{\circ}=(68.1 \pm 4.2) \mathrm{J} \cdot \mathrm{mol}^{-1} \cdot \mathrm{K}^{-1}$, and for the apparent molal heat capacity at infinite dilution, $C_{p 2} \stackrel{\circ}{=}(178 \pm 15) \mathrm{J} \cdot \mathrm{mol}^{-1} \cdot \mathrm{K}^{-1}$.

Keywords: Calorimetry; 2,4-dioxopyrimidine; nucleic acid bases; 2,4 (1H,3H)-pyrimidinedione; thermochemistry; uracil: density, enthalpy of solution, entropy of solution.

\section{Introduction}

Three earlier papers in this series have described our measurements of the enthalpies of solution in water of adenine, thymine, and cytosine $[1,2,3] .{ }^{1}$ Similar information is given in this paper for uracil, a pyrimidine base of the nucleic acids. The structural formula [4] is<smiles>O=c1[nH]ccc(=O)c(=O)[nH]1</smiles>

The solubility in $\mathrm{H}_{2} \mathrm{O}$ is $3.0 \mathrm{~g} \cdot \mathrm{L}^{-1}[5]^{2}$ at $298 \mathrm{~K}$; uracil sublimes and decomposes before melting. Only one value for

\footnotetext{
${ }^{1}$ Figures in brackets indicate the literature references at the end of this paper.

${ }^{2}$ The National Bureau of Standards (U.S.) has recently recommended the use of the symbol "L" for the liter, the metric unit commonly used to measure volume [6].
}

the enthalpy of solution in $\mathrm{H}_{2} \mathrm{O}$ has been reported previously [7], and that was a small part of a study of transfer coefficients where the purity of the samples was not a major consideration.

In this series, characterization of the samples is emphasized in order to assign realistic uncertainty limits to the measured values for the enthalpy of solution. Samples of uracil as received from three commercial sources are compared with samples which were further purified by sublimation and by recrystallization from $\mathrm{H}_{2} \mathrm{O}$ and from ethyl alcohol. Enthalpies of solution of uracil in $\mathrm{H}_{2} \mathrm{O}$ were measured in the temperature range, 298 to $325 \mathrm{~K}$, and in the concentration range, 3 to $45 \mathrm{mmol} \cdot \mathrm{kg}^{-1}$.

\section{The Uracil (Ura) Samples}

Enthalpies of solution were measured on three uracil samples as received from commercial sources. ${ }^{3}$ The following information about these samples was obtained primarily from

\footnotetext{
${ }^{3}$ The information presented in this paper is in no way intended as an endorsement nor a condemnation of any of the materials or services used. Commerical sources are named only for specific identification.
} 
labels, catalogs, and brochures supplied by the manufacturer:

Ura 1 Calbiochem, Cat. No. 6630, Lot 802190, Grade A, 100 g, received about 1970-exact date unknown. Analysis: Nitrogen, 25.10\%. Spectra at pH 7: 250/260 0.83, 280/260 0.16, $\lambda \max 260 \mathrm{~m} \mu, \epsilon \max 8130$. Chromat. Homogeneous.

$\mathbf{U r a}_{\mathbf{n}} 2$ Eastman Organic Chemicals, Cat. No. 2504, Lot 24A, $10 \mathrm{~g}$ received about 1970 - exact date unknown. MP $335^{\circ}$ dec. (This material had an off-white color when compared with Ura 1 and 3.)

Ura 3 E-M Laboratories, Cat. No. 8460, for biochemistry, Lot 4955541, $100 \mathrm{~g}$ received August 1974. Type Analysis: Assay 98\% (ref. to dried substance). Optical properties, measured values at $\mathrm{pH} 7: \lambda \max 260$, $\mathrm{E}_{250} / \mathrm{E}_{260} 0.83 \pm 0.02, \mathrm{E}_{280} / \mathrm{E}_{260} 0.20 \pm 0.02, \mathrm{E}_{290} / \mathrm{E}_{260}<0.02$. Thin layer chromatography: Layer: TLC plates PEI-Cellulose F, precoated, Solvent: $1 \mathrm{M} \mathrm{NaCl}$ solution, $R f$ value: $\sim 0.7$.

Ura 4 Same as Ura 3 except 25 g received November 1974.

Portions of Ura 3 were further purified in this laboratory according to the following procedures:

Ura 3a and 3b were recrystallized from $\mathrm{H}_{2} \mathrm{O}$ and $90 \%$ ethyl alcohol and dried according to the procedures described in detail for Thy $3 \mathrm{a}$ and $3 \mathrm{~b}$ [2]. Approximately $1.5 \mathrm{~g}$ of Ura $3 \mathrm{a}$ and $14 \mathrm{~g}$ of Ura $3 \mathrm{~b}$ were obtained as the final products.

Ura 3c was vacuum-sublimed according to the procedures described previously for Ade $1 c$ and $5 c$ [1]. The sublimation temperature was 425 to $428 \mathrm{~K}$. After about $40 \mathrm{~h}$ the sublimation was stopped with some of the unsublimed material remaining at the bottom of the vessel. The vessel, still under vacuum, was transferred to a dry box where the sublimate was removed. It was very finely divided and adhered tightly to the condenser (unlike thymine and cytosine which were fluffy and easily removed). The uracil sublimate was chipped off the glass surface, with a stainless steel spatula, in flakes which were shiny on the side which had been next to the glass surface. However, the glass surface showed no evidence of having been attacked by the sublimate. Transfers of this material to the calorimetric sample holder were done in a dry box.

Ura 3d was the unsublimed residue from the sublimation where Ura $3 c$ was the product. The residue was discolored with some light brown or beige material which was undoubtedly a decomposition product.

\subsection{Characterization of the Samples}

The purity of the uracil could not be determined from freezing-temperature measurements because it decomposes before melting. Therefore, a search for impurities was made, and some of the intensive properties of the samples were measured to define the materials on which enthalpies of solution were determined.

In this laboratory the samples were analyzed for $\mathrm{H}_{2} \mathrm{O}$ and volatile matter, impurities by paper and thin layer chromatography (TLC), and approximate values for the density were measured. Other laboratories contributed measurements of the enthalpy of combustion, heat capacity of the crystalline materials, and analyses of emission spectra, x-ray powder patterns, and elemental composition.

\subsubsection{Density, Volatile Matter, and $\mathrm{H}_{2} \mathrm{O}$}

The densities of Ura 1,2 , and 3 as received were measured by displacement of $\mathrm{CCl}_{4}$ (analytical reagent for which the specified density at $298 \mathrm{~K}$ was in the range of 1.583 to $1.585 \mathrm{~g} \cdot \mathrm{mL}^{-1}$ ). Details of the procedure were described previously [1]. The density of the $\mathrm{CCl}_{4}$ under laboratory conditions was $1.5897 \mathrm{~g} \cdot \mathrm{mL}^{-1}$ which is the mean of three measurements with an average deviation of \pm 0.0008 $\mathrm{g} \cdot \mathrm{mL}^{-1}$. The measured densities for uracil are as follows: Ura $1,1.607$ and $1.595 \mathrm{~g} \cdot \mathrm{mL}^{-1}$; Ura 2, $1.605 \mathrm{~g} \cdot \mathrm{mL}^{-1}$; and Ura $3,1.594 \mathrm{~g} \cdot \mathrm{mL}^{-1}$. It was determined that the uracil was not soluble in the $\mathrm{CCl}_{4}$ by filtering and weighing the dried samples after the density measurements; the loss in mass was 0.2 percent or less. When the filtrates were evaporated to dryness at room temperature, there was no visible residue. The mean of the four density measurements, (1.600 \pm $0.011) \mathrm{g} \cdot \mathrm{mL}^{-1}$, was used in calculating the buoyancy factor, 1.00060 , for the uracil mass corrections in this work. This value for the density of uracil is in good agreement with those obtained from single crystals: $1.590 \mathrm{~g} \cdot \mathrm{mL}^{-1}$ from $\mathrm{x}$-ray data and $1.625 \mathrm{~g} \cdot \mathrm{mL}^{-1}$ by floatation [8].

The following observations were made on the volatility and hygroscopicity of the uracil samples:

Three portions ( 1 to $4 \mathrm{~g}$ ) of Ura 1 and of Ura 2 (contained in covered flat aluminum moisture dishes) were weighed, then heated at $340 \mathrm{~K}$ under vacuum (see [1] for details) for 4 $\mathrm{h}$, cooled in a desiccator, and reweighed; the procedure was repeated with 2-h heating periods for a total of 10 to $14 \mathrm{~h}$ of heating at which time the materials had either reached constant mass or a constant rate of loss in mass. The samples of Ura 1 apparently reached constant mass after $6 \mathrm{~h}$ heating with a loss of $\sim 0.4 \mathrm{mg} \cdot \mathrm{g}^{-1}$; for those of Ura 2 , the loss was $\sim 0.9 \mathrm{mg} \cdot \mathrm{g}^{-1}$. These samples were subsequently exposed to the atmosphere occasionally over a period of 2 years. A second series of observations was then made similar to those described above except that the vacuum drying was at $375 \mathrm{~K}$ and single 3 -g portions were taken of Ura $1,2,3$, and 4 . After about $6 \mathrm{~h}$ of heating, Ura 1 again appeared to be at nearly constant mass with a loss of $\sim 0.6 \mathrm{mg} \cdot \mathrm{g}^{-1}$; Ura 3 and 4 were also at nearly constant mass, with a loss of $\sim 0.9$ $\mathrm{mg} \cdot \mathrm{g}^{-1}$. However, Ura 2 lost $1.6 \mathrm{mg} \cdot \mathrm{g}^{-1}$ during the first 4 $\mathrm{h}$ and continued loss at a rate of $\sim 0.1 \mathrm{mg} \cdot \mathrm{g}^{-1} \cdot \mathrm{h}^{-1}$; if this rate of loss (assumed to be due to sublimation) is extrapolated to zero time, we obtain the loss due to volatile matter, $\sim 1.2$ $\mathrm{mg} \cdot \mathrm{g}^{-1}$, which is only slightly larger than the mass loss at $340 \mathrm{~K}$.

At this time, the dish containing Ura 1 was opened exposing the sample to the atmosphere (35\% relative humid- 
ity) while on a balance. After $7 \mathrm{~h}$, a gain of $\sim 0.8 \mathrm{mg} \cdot \mathrm{g}^{-1}$ $(\sim 0.1 \%)$ was observed but there was no change after an additional $18 \mathrm{~h}$. (The gain in mass corresponding to the formation of the monohydrate would be 16\%.) This agrees with the observation of Falk [9] that uracil does not form hydrates even at 93 percent relative humidity. Therefore, the samples for calorimetric measurements (except the product of sublimation, Ura 3c) were transferred to the sample holder in the laboratory atmosphere (the maximum exposure time was approximately $10 \mathrm{~min}$ ).

A third series of vacuum drying observations was made at $375 \mathrm{~K}$; these were at $\sim 22$-h heating intervals for about 140 h. This series included the same samples of Ura 1 and 2 discussed above and the recrystallized samples of Ura 3a and $3 \mathrm{~b}$ (in glass weighing bottles) which had been previously dried overnight at $340 \mathrm{~K}$ at atmospheric pressure. Ura 1 lost mass at the constant rate of about $50 \mu \mathrm{g} \cdot \mathrm{g}^{-1} \cdot \mathrm{h}^{-1}$ and Ura 2 at $90 \mu \mathrm{g} \cdot \mathrm{g}^{-1} \cdot \mathrm{h}^{-1}$. These rates would not have been detected in the shorter heating intervals. Ura 3a lost mass at the rate of about $15 \mu \mathrm{g} \cdot \mathrm{g}^{-1} \cdot \mathrm{h}^{-1}$ for the first $70 \mathrm{~h}$; thereafter the rate increased to about $50 \mu \mathrm{g} \cdot \mathrm{g}^{-1} \cdot \mathrm{h}^{-1}$. Ura 3b showed a constant rate of loss in mass of $15 \mu \mathrm{g} \cdot \mathrm{g}^{-1} \cdot \mathrm{h}^{-1}$ for $115 \mathrm{~h}$ of heating. These constant rates of mass loss are assumed to be sublimation rates under these conditions; however the abrupt increase observed in the sublimation rate for Ura 3a cannot be explained since the materials were heated simultaneously.

It is assumed that the best value for volatile matter in the commercial samples as received is obtained by extrapolating the results obtained in the second series of vacuum-drying to zero time. This gives the following values for volatile matter in mass percent: Ura 1, 0.04; Ura 2, 0.12; Ura 3 and 4, 0.05 . The recrystallized samples, Ura $3 \mathrm{a}$ and $3 \mathrm{~b}$, which were vacuum dried for extended periods, and the sublimed sample, Ura 3c, are assumed to be free of volatile impurities.

Karl Fischer titrations for $\mathrm{H}_{2} \mathrm{O}$ (as described [2]) indicated $0.05,0.30,0.10$, and 0.13 mass percent for Ura $1,2,3$, and 4 , respectively. The uncertainty in these measurements is estimated to be about \pm 0.1 mass percent. The solubility of the uracil samples in the methanol solvent was about onefourth that of the other pyrimidine bases, thymine and cytosine. These results support the assumption that $\mathrm{H}_{2} \mathrm{O}$ was the volatile matter determined by vacuum-drying. Corrections to the calorimetric measurements for $\mathrm{H}_{2} \mathrm{O}$ in the samples were based on the volatile matter determinations because the uncertainties were smaller than those in the titrations.

\subsubsection{Other Analyses}

The emission spectra ${ }^{4}$ of Ura 1, 2, 3, and 4 indicated (in addition to the possible background impurity limits listed previously [1]) the presence in Ura 2 of 0.02 mass percent of $\mathrm{Fe}$ and $\mathrm{Si}$, and a trace of $\mathrm{Mg}$ and a trace of $\mathrm{Ag}$ in Ura 3 and 4. These small amounts of impurities are not regarded as a source of significant error in the enthalpy of solution measurements.

Duplicate elemental analyses ${ }^{5}$ of Ura 1, 2, 3, and 3a are given in table 1 where the estimated uncertainty in each determination is 0.2 mass percent. The $\mathrm{C}$ and $\mathrm{N}$ analyses for all of the samples are somewhat higher than those of the theoretical composition of anhydrous uracil. The oxygen is high on Ura 1 and 3 a but a little low on Ura 2. These departures from the theoretical composition cannot be explained on the basis of any of the other analytical data such as $\mathrm{H}_{2} \mathrm{O}$ or volatile matter. Ura 3 appears to be closer to the theoretical composition of anhydrous uracil than the recrystallized sample, Ura 3a which had been vacuum dried. This would indicate that all occluded $\mathrm{H}_{2} \mathrm{O}$ may not have been removed during the vacuum drying. In general, there appears to be greater variation in the purity of these uracil samples than was found in the other bases previously described in

${ }^{4}$ Analyses by J. A. Norris, Center for Analytical Chemistry, National Measurement Laboratory, National Bureau of Standards.

${ }^{5}$ By Micro Analysis, Inc. Wilmington, DE.

Table 1. Elemental analyses of uracil samples.

\begin{tabular}{l|c|c|c|c|c|c|c|c}
\hline Substance & $\begin{array}{c}\text { Emp1rical } \\
\text { Formula }\end{array}$ & $\begin{array}{c}\text { Molecular } \\
\text { Mass }\end{array}$ & C & H & 0 & $\begin{array}{c}\text { N } \\
\text { (Kjeldah1) }\end{array}$ & $\begin{array}{c}\text { Sulfated } \\
\text { Ash }\end{array}$ & mass percent \\
\hline
\end{tabular}

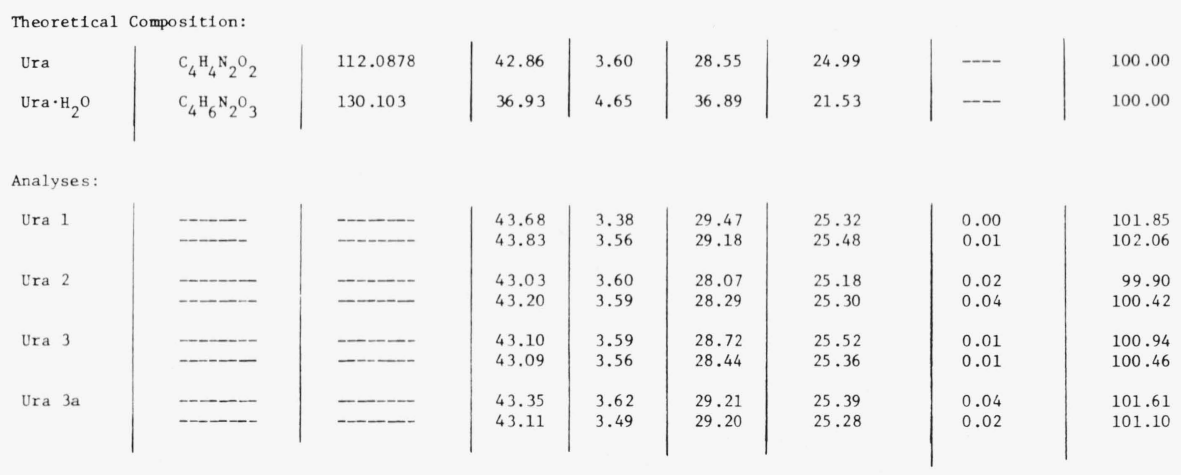


this series. However, there appears to be little if any hydration in the samples.

Paper and TLC analyses of the four commercial uracil samples as received (Ura 1, 2, 3, and 4) produced the $R_{f}$ values (distance traveled by the major component/distance traveled by the solution front) given in table 2. Four carrier solutions were used with Whatman No. 1 and No. 40 chromatography papers and with glass TLC plates coated with MN300F Cellulose (with fluorescent indicator). Details of procedures including observations regarding background and sensitivities were discussed previously [1]. Our $R_{f}$ values are compared in table 2 with those given on page 152-3 of the National Academy of Sciences (NAS) publication [10]. The latter are somewhat lower than our values but still within variations to be expected under different experimental conditions. The estimated uncertainty in reading the chromatograms is $\pm 0.02 R_{f}$ unit. In the four carrier solutions, the four uracil samples have the same $R_{f}$ values within the uncertainty; and no impurities were detected in any of the samples. Thus, all four samples are of equal purity (probably $95 \%$ or more) within the limits of chromatographic detection. Table 2. R $\mathrm{R}_{\mathrm{f}}$ values for the uracil samples in $\mathrm{NH}_{4} \mathrm{OH}\left(\mathrm{aq}, 1 \mathrm{~mol} \cdot \mathrm{L}^{-1}\right.$ ) solutions on fluorescent TLC plates and two papers
with four carrier solutions, $\mathrm{A}, \mathrm{B}, \mathrm{C}$, and $\mathrm{D}$.

\begin{tabular}{|c|c|c|c|c|c|c|c|c|c|c|c|c|}
\hline \multirow{2}{*}{$\begin{array}{c}\text { Uraci1 } \\
\text { Sample No. }\end{array}$} & \multicolumn{3}{|c|}{$A^{a}$} & \multicolumn{3}{|c|}{$\mathrm{B}^{\mathrm{a}}$} & \multicolumn{3}{|c|}{$c^{a}$} & \multicolumn{3}{|c|}{$D^{a}$} \\
\hline & TLC & $\mathrm{P}-1$ & $\mathrm{P}-40$ & TLC & $\mathrm{P}-1$ & $P-40$ & TLC & $\mathrm{P}-1$ & $P-40$ & TLC & $\mathrm{P}-1$ & $P-40$ \\
\hline 1 & 0.65 & 0.69 & 0.70 & 0.57 & 0.62 & 0.70 & 0.71 & 0.71 & - & 0.89 & 0.78 & 0.78 \\
\hline 2 & .65 & .67 & .71 & .57 & .62 & .69 & .72 & .71 & - & .90 & .78 & .77 \\
\hline 3 & .65 & .69 & .72 & .57 & .62 & .69 & .72 & .71 & - & .93 & .77 & .76 \\
\hline 4 & .64 & .66 & .72 & .56 & .62 & .71 & .72 & .71 & - & .91 & .78 & .75 \\
\hline $\operatorname{NAS}\left[\mathbb{L}^{\mathrm{b}}\right]^{\mathrm{b}}$ & & & 0.63 & & & 0.59 & & & 0.70 & & & 0.70 \\
\hline
\end{tabular}

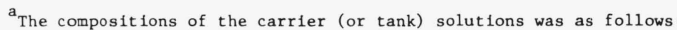

Soln A: 5 parts of iso-butyric acid +3 parts of $\mathrm{NH}_{4} \mathrm{OH}\left(\mathrm{aq}, 0.5 \mathrm{~mol} \cdot \mathrm{L}^{-1}\right.$ ).

Soln B: 7 parts of 1so-propyl alcohol +1 part of conc. $\mathrm{NH}_{4} \mathrm{OH}+2$ parts of $\mathrm{H}_{2} \mathrm{O}$.

Soln C: 7 parts of $95 \%$ ethyl alcohol +3 parts of sodium acetate (aq, $1 \mathrm{~mol} \cdot \mathrm{L}^{-1}$ ).

Soln D: $\mathrm{H}_{2} \mathrm{O}$ adjusted to $\mathrm{pH} 10$ with $\mathrm{NH}_{4} \mathrm{OH}\left(\sim 1\right.$ drop of conc. $\mathrm{NH}_{4} \mathrm{OH}$ in $\left.300 \mathrm{~mL} \mathrm{H}_{2} \mathrm{O}\right)$.

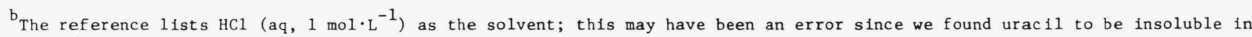
$\mathrm{HCl}\left(\mathrm{aq}, 1 \mathrm{~mol} \cdot \mathrm{L}^{-1}\right)$.

\subsubsection{Calorimetric Characterization}

Measurements ${ }^{6}$ of the heat capacity of our samples of crystalline uracil at $298 \mathrm{~K}$ using a drop micro-calorimeter gave the following values for $C_{p}{ }^{\circ}$ : Ura $1,(1.075 \pm 0.008)$ $\mathrm{J} \cdot \mathrm{g}^{-1} \cdot \mathrm{K}^{-1}$, and Ura 3, (1.075 \pm 0.004$) \mathrm{J} \cdot \mathrm{g}^{-1} \cdot \mathrm{K}^{-1}[11]$. The value used in later calculations was (120.5 \pm 1.8$)$ $\mathrm{J} \cdot \mathrm{mol}^{-1} \cdot \mathrm{K}^{-1}$.

Two measurements ${ }^{7}$ of the enthalpy of combustion of Ura 1 were made in June 1974 using an adiabatic bomb calorimeter described previously [12]. The ratios of the $\mathrm{CO}_{2}$ in the actual products of combustion to the theoretical $\mathrm{CO}_{2}$ in the products of combustion of pure uracil were 0.999 and 0.997 for the two measurements; this is another indication of the purity of the sample. The following values for the enthalpy of combustion were obtained: $\Delta H_{c}{ }^{\circ}(298.15 \mathrm{~K})=-1717.73$ and $-1717.36 \mathrm{~kJ} \cdot \mathrm{mol}^{-1}$. These may be compared with the value of $(-1716.14 \pm 0.28) \mathrm{kJ} \cdot \mathrm{mol}^{-1}[13]$ from 9 measurements on a commercial sample of unknown purity; the products of combustion were not analysed.

${ }^{6}$ By Ernesto Friere, Department of Pharmacology, University of Virginia, Charlottesville, VA.

${ }^{7}$ By Walter H. Johnson, Center for Thermodynamics and Molecular Science, National Measurement Laboratory.

\section{Enthalpy of Solution}

The platinum-lined adiabatic solution calorimeter previously described [14] was used for the 29 measurements (between January 1974 and October 1976) of the enthalpy of solution of 7 uracil samples in water reported here. The calorimeter vessel contained approximately $300 \mathrm{~mL}$ of distilled water. The platinum sample holder has interchangeable cylinders; the two used in this work were 0.7 and $3.0 \mathrm{~mL}$ in volume. Since the solution of uracil proceeded without difficulty, a moderate stirring rate, 550 revolutions per min, was used.

In each experiment, the system was calibrated electrically before and after the uracil reaction. During the endothermic solution reactions, precisely measured electrical energy was added in most experiments to prevent a decrease in the calorimeter temperature and loss of adiabatic conditions. The calorimeter temperature was measured with a quartz oscillator thermometer system [1, 14]. The calibrations of this system and those of the standard cell and standard resistors used in the electrical energy measurements were given previously [1]. The general procedures for making the measurements and the methods for calculations were de- 
scribed in detail [14]. The 1975 Table of Atomic Weights [15] was used in calculating the following molecular masses used in this work: uracil, 112.0878 and $\mathrm{H}_{2} \mathrm{O}, 18.0152$. For energy conversions, 1 thermochemical calorie $=4.184$ joules.

The data for the enthalpy of solution measurements of uracil in water are given in table 3. The Experiment Number is a serial number for experiments with this calorimeter and indicates the chronological order of the experiments. The Reaction Period is the elapsed time between initiating the reaction and the beginning of the rating period which follows the reaction. $T_{\text {reaction }}$ is the mean of the initial and final temperatures of reaction. The estimated calorimetric uncertainty for an experiment, Cal. Unc., is based on the duration of the reaction, the magnitude of the temperature change from the reaction, and the standard deviation of the slope of the rating period following the reaction (see [1] for details). The heat of the solution reaction, $Q_{\text {reaction, }}$ is given by the following equation:

$$
Q_{\text {reaction }}=\Delta T_{\text {reaction }}\left(\frac{\epsilon_{i}+\epsilon_{f}}{2}\right)-q_{\text {vap }}
$$

where the electrical energy equivalents (in $\mathrm{J} \cdot \mathrm{K}^{-1}$ ) of the initial and final systems are $\epsilon_{i}$ and $\epsilon_{f}$, the temperature change due to the solution reaction is $\Delta T_{\text {reaction, }}$ and the heat of vaporization of water into the air space in the sample holder upon opening is $q_{\mathrm{vap}} . \Delta T_{\text {reaction }}=\Delta T-$ EIt $\left(\frac{\epsilon_{i}+\epsilon_{f}}{2}\right)^{-1}$ where $\Delta T$ (not given in table 3) is the net

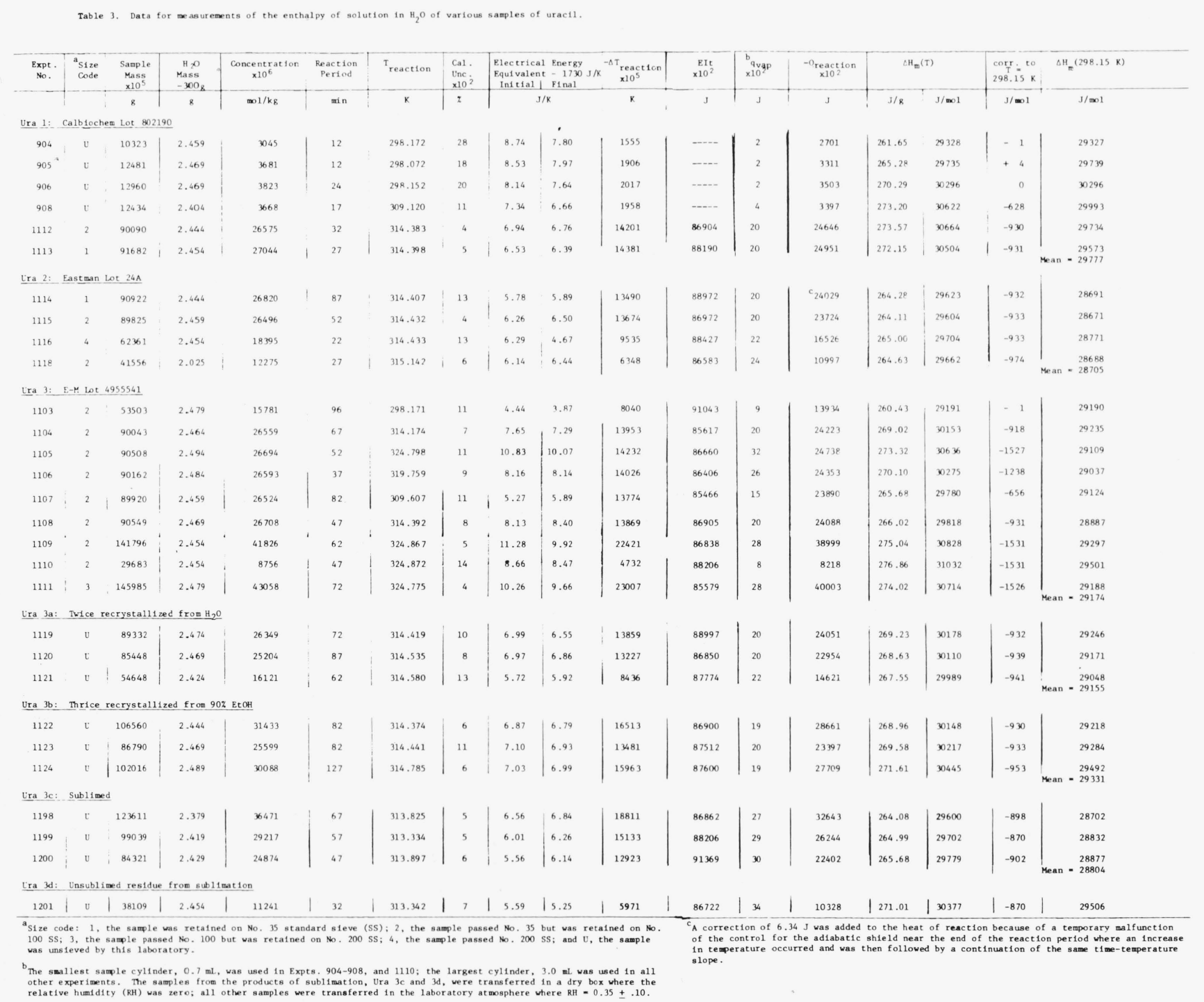


temperature change resulting from the endothermic solution reaction and the electrical energy added, EIt. $q_{\mathrm{vap}}=\Delta H_{\mathrm{vap}}$ $\left(\mathrm{V}-\frac{s}{d}\right)(1-R H)$ where $\Delta H_{\mathrm{vap}}$ is the enthalpy of vaporization of water per unit volume at the mean temperature of reaction, $V$ is the internal volume of the sample holder, $s$ is the mass of sample, $d$ is the density of the sample, and $R H$ is the relative humidity of the atmosphere in which the sample was transferred to the sample holder (for the transfer in the dry box, $R H=0$; in the laboratory atmosphere, $R H$ $=0.35 \pm 0.10)$. The enthalpy of solution per gram at the temperature of reaction and at the concentration of the measurements is $\Delta H_{m}(T)=-Q_{\text {reaction }}(\text { Sample mass) })^{-1}$.

The lengths of the reaction periods given in table 3 are dependent on the temperature of reaction, the amount of sample, and the sample itself. For example, in Expt. No. 1112 , 1115, and 1104 with Ura 1, 2, and 3 at the same temperature and concentration, the reaction periods were 32 , 52 , and $67 \mathrm{~min}$, respectively. In some preliminary experiments, incomplete reactions were believed to have been caused by large particles in the samples; sieving the sample greatly reduced the problem. However, small amounts of undissolved material were visible at the end of Expt. No. 1103 and 1107 which were both at lower temperatures than most of the other experiments. The measurements with Ura 2 using various particle sizes (see size code in table 3 ) indicate that the smaller particles dissolved more quickly, but there was no significant difference in the enthalpies of solution. Apparently sieving was not necessary in the samples which had been vacuum-dried (Ura 3a, 3b, 3c, and 3d). Under comparable conditions, the reaction periods for Ura 1 were generally shorter than for the other samples; and it will be shown later that the $\mathrm{pH}$ of the final solution and the enthalpy of solution were somewhat larger than those of the other samples; the reason for this is unknown.

The change in the enthalpy of solution of uracil with temperature, $\Delta C_{p}$, was obtained from 14 experiments with Ura 3, 3a, and 3b (omitting Expt. 1110 because of the low concentration). These data are given in table 3 and plotted in figure 1 where the straight line is the result of a least squares fit to the data for $T_{\text {reaction }}$ and $\Delta H_{m}(T)$ to a linear equation. The slope of this line is $(57.3 \pm 5.9) \mathrm{J} \cdot \mathrm{mol}^{-1} \cdot \mathrm{K}^{-1}$ and the uncertainty is the standard error. Thus, in the temperature range, $298 \mathrm{~K}<T<325 \mathrm{~K}, \Delta C_{p}=(57 \pm 13) \mathrm{J} \cdot \mathrm{mol}^{-1} \cdot \mathrm{K}^{-1}$ with the uncertainty at the 95 percent confidence level. This value was used to calculate the correction to $T=298.15 \mathrm{~K}$ given in table 3 which was added to $\Delta H_{m}(T)$ to obtain the enthalpy of solution at the standard temperature and at the concentration of the measurement.

In figure 1 the radius of a circle is equal to the estimated calorimetric uncertainty (about 0.1\%) for each experiment. It is evident that about one-half of the circles are not close to the line. Sample inhomogeneity is probably the cause of this

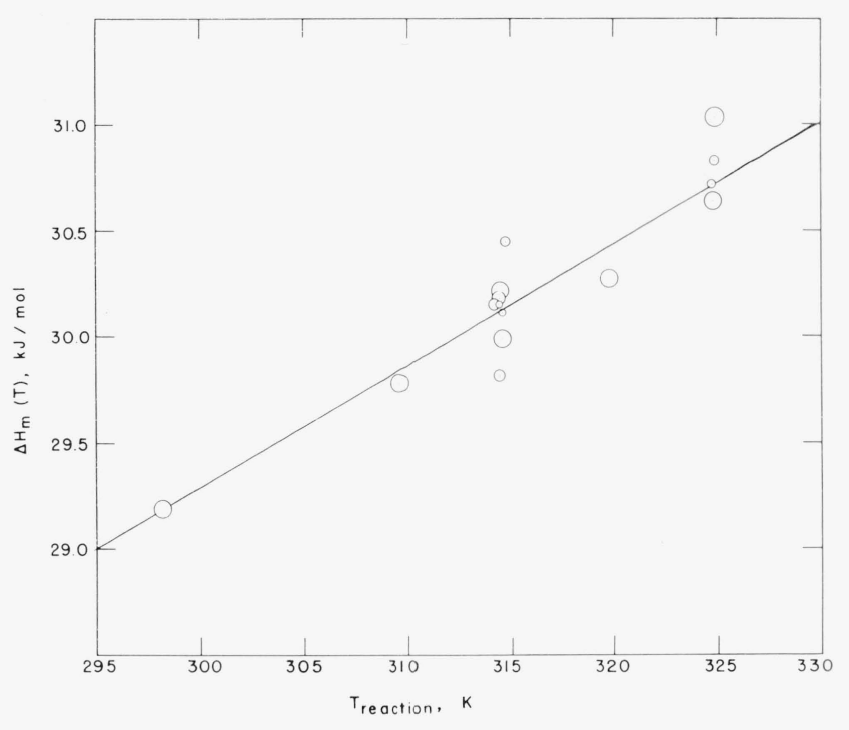

FIGURE 1. Plot showing the relationship of the enthalpy of solution of uracil in water and the temperature of reaction. The slope of the straight line is $\Delta C_{p}=(57 \pm 13) \mathrm{J} \cdot \mathrm{mol}^{-1} \cdot \mathrm{K}^{-1}$.

additional uncertainty of 0.1 to 0.2 percent of the enthalpy of solution.

Figure 2 is a plot of all values for $\Delta H_{m}(298.15 \mathrm{~K})$ in table 3 versus the concentration of uracil in the final solutions. The points for the various samples are distinguished by different symbols, and the radius of a circle (or a circle circumscribed by the other geometric figures) is equal to the estimated calorimetric uncertainty for the experiment. There appears to be no significant change in the enthalpy of solution in the concentration range of 10 to $45 \mathrm{mmol} \cdot \mathrm{kg}^{-1}$ based on the data for Ura 3 (open circles); the one value near $9 \mathrm{mmol} \cdot \mathrm{kg}^{-1}$ is a little larger than the others, but may still be within the uncertainty due to sample inhomogeneity.

The four values for Ura 1 (squares in fig. 2) between 3 and $4 \mathrm{mmol} \cdot \mathrm{kg}^{-1}$ suggest the possibility of an increase in the enthalpy of solution at the lower concentration, however, the two values near $27 \mathrm{mmol} \cdot \mathrm{kg}^{-1}$ are also higher than those for the other samples. Thus, these higher values for Ura 1 are probably characteristic of this sample. The larger calorimetric uncertainties at the low concentrations are to be expected.

The measurements with Ura 3 (open circles) agree within the homogeneity uncertainty with those of the recrystallized samples, Ura 3a (right half-shaded circles) and Ura 3b (left half-shaded circles). The three experiments with the sublimed sample, Ura 3c (lower half-shaded circles), are all at the lower limit of the range of measurements with Ura 3, 3a, and $3 \mathrm{~b}$; and the single measurements with the unsublimed residue, Ura $3 \mathrm{~d}$ (upper half-shaded circle) is at the upper limit of that range. The four measurements of Ura 2 (diamonds) are lower than any of the others. 


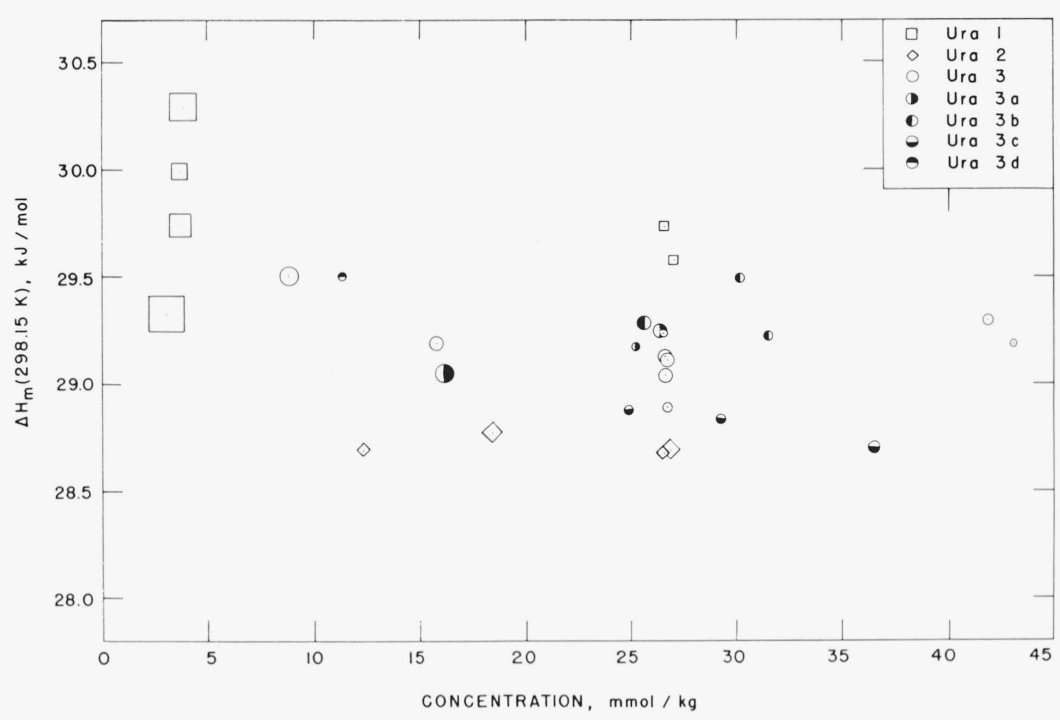

FIgURE 2. Plot showing that the enthalpy of solution of uracil in water is independent of concentration in this range, and that there are differences between various samples which cannot be resolved on the basis of analytical data.

See text for description of the samples represented by the various symbols.

The calorimetric measurements on Ura 1, 2, and 3 were made on the materials as received (except for sieving in some cases) and without drying or further purification. If the mean values for $\Delta H_{m}(298.15 \mathrm{~K})$ are corrected for $\mathrm{H}_{2} \mathrm{O}$ found in the determination of volatile matter (Ura 1, $0.25 \mathrm{~mol} \%$; Ura 2, $0.75 \mathrm{~mol} \%$; and Ura 3, $0.31 \mathrm{~mol} \%$ ) we obtain 29.85, 28.92 , and $29.26 \mathrm{~kJ} \cdot \mathrm{mol}^{-1}$, respectively, for the mean enthalpies of solution. It was assumed that the other samples, which were vacuum dried for long periods, contained no water although the elemental analysis of Ura 3a introduces a question as to the validity of this assumption.

Measurements of enthalpies of solution have detected differences in the various uracil samples which were not evident from the analytical data; this was also true for adenine, thymine, and cytosine [1, 2, 3]. The mean values for $\Delta H_{m}(298.15 \mathrm{~K})$ in $\mathrm{kJ} \cdot \mathrm{mol}^{-1}$, corrected for $\mathrm{H}_{2} \mathrm{O}$ where it was measured, are (in descending order): Ura 1, $29.85 \pm$ $0.35 \mathrm{~kJ} \cdot \mathrm{mol}^{-1}$; Ura 3d, 29.5l; Ura 3b, $29.33 \pm 0.36$; Ura $3,29.26 \pm 0.13$; Ura 3a, 29.16 \pm 0.25; Ura 2, $28.92 \pm$ 0.07 ; and Ura $3 c, 28.80 \pm 0.23$. The experimental uncertainties are at the 95 percent confidence level. The single value for Ura 3d was eliminated from consideration because of the apparent decomposition evidenced by the discoloration of the sample. The low value for the sublimed sample, Ura $3 c$, was rejected because of the probability of a tautomer or of a lower order of crystallinity as was found for sublimed adenine [1]. Ura 3 was probably of high purity because the enthalpies of solution of the recrystallized sample, Ura 3a and $3 \mathrm{~b}$, agreed within the uncertainties with that of the parent material. There was no analytical evidence that the purities of Ura 1 and Ura 2 were higher or lower than that of Ura 3. Therefore, the mean of the five values for Ura 1, 2, 3, $3 \mathrm{a}$, and $3 \mathrm{~b}$ was taken as our best value for the enthalpy of solution of uracil in water, and $\Delta H(298.15 \mathrm{~K})=(29.3 \pm$ 1.2) $\mathrm{kJ} \cdot \mathrm{mol}^{-1}$ in the concentration range 10 to 45 $\mathrm{mmol} \cdot \mathrm{kg}^{-1}$. The assigned uncertainty is twice the square root of the sum of the squares of the individual uncertainties. This uncertainty is large enough to include uncertainties in the measurements and in the purity of the samples.

The $\mathrm{pH}$ of solutions of Ura 1, 2, and 3 containing approximately $25 \mathrm{mmol} \cdot \mathrm{kg}^{-1}$ was measured and found to be significantly higher in the solution of Ura 1 than in those of Ura 2 or 3 ; the measured $\mathrm{pH}$ was 5.2 for Ura 1, 4.2 for Ura 2 , and 4.5 for Ura 3. Since the $\mathrm{H}^{+}$concentration of the final solutions was 4 to 5 orders of magnitude smaller than the ionization constant, $3 \times 10^{9}[4]$, and the correction to infinite dilution was negligibly small, our measured value for the enthalpy of solution was considered to be equal to that at infinite dilution.

\section{Discussion and Summary}

Larsen and Magid [7] reported (26.78 \pm 0.84$) \mathrm{kJ} \cdot \mathrm{mol}^{-1}$ for the enthalpy of solution in $\mathrm{H}_{2} \mathrm{O}$ at infinite dilution for a sample of uracil which was "carefully purified by standard techniques"; no analytical data were given. The results from six measurements were "extrapolated to infinite dilution by linear least squares analysis." The mean of four of these measurements in the concentration range of our work is $(21.98 \pm 0.13) \mathrm{kJ} \cdot \mathrm{mol}^{-1}$ (the uncertainty is the standard 
deviation of the mean) which is 25 percent lower than our value. However, the uncertainty of the extrapolated value falls within the lower limit of our assigned uncertainty.

From their solubility measurements, Scruggs et al. [5] calculated $\Delta H\left(37^{\circ} \mathrm{C}\right)=6700 \mathrm{cal} \cdot \mathrm{mol}^{-1}$ for the enthalpy of solution of uracil in water. Using the $\Delta C_{p}$ value determined in this work, we obtain $6536 \mathrm{cal} \cdot \mathrm{mol}^{-1}$ or $27.34 \mathrm{~kJ} \cdot \mathrm{mol}^{-1}$ at $298.15 \mathrm{~K}$ which is nearly 7 percent less than our value but within the uncertainty assigned.

We have shown that significant differences exist in the enthalpies of solution of uracil samples from different sources and these differences cannot be resolved on the basis of the analytical results. Until the purity of uracil samples can be defined more accurately than was done in this work, the value for the enthalpy of solution in water is taken as

$$
\Delta H^{\circ}(\infty, 298.15 \mathrm{~K})=(29.3 \pm 1.2) \mathrm{kJ} \cdot \mathrm{mol}^{-1}
$$

and

$$
\Delta C_{p}{ }^{\circ}=(57 \pm 13) \mathrm{J} \cdot \mathrm{mol}^{-1} \cdot \mathrm{K}^{-1}, 298 \mathrm{~K}<T<325 \mathrm{~K} .
$$

No change in the enthalpy of solution with concentration was detected in this work.

Other useful thermodynamic data may be calculated with these values. The apparent molal heat capacity of uracil at infinite dilution, $C_{p 2}{ }^{\circ}$, is $(178 \pm 15) \mathrm{J} \cdot \mathrm{mol}^{-1} \cdot \mathrm{K}^{-1}$ which is the sum of the $\Delta C_{p}{ }^{\circ}$ (above) and the $C_{p}{ }^{\circ}$ for the crystalline uracil given in section 2.1.3. From the solubility measurements of Scruggs, et al. [5] we calculate the molal solubility at $298.15 \mathrm{~K}$ to be $(0.0269 \pm 0.0013) \mathrm{mol} \cdot \mathrm{kg}^{-1}$, and $\Delta G^{\circ}$ $=-R T \ln m=9.0 \pm 0.4 \mathrm{~kJ} \cdot \mathrm{mol}^{-1}$. Combining this with our value for the enthalpy of solution we obtain

$$
\Delta S^{\circ}=\frac{\Delta H^{\circ}-\Delta G^{\circ}}{T}=(68.1 \pm 4.2) \mathrm{J} \cdot \mathrm{mol}^{-1} \cdot \mathrm{K}^{-1} .
$$

The average of 4 measurements of the density of uracil was $(1.60 \pm 0.01) \mathrm{g} \cdot \mathrm{mL}^{-1}$.

The author expresses her appreciation to R. L. Biltonen of the University of Virginia for the measurement of the heat capacities of the crystalline samples, and for his interest and consultations during this work.

\section{References}

[1] Kilday, M. V., J. Res. Nat. Bur. Stand. (U.S.), 83, No. 4, 347-370 (July-August 1978).

[2] Kilday, M. V., J. Res. Nat. Bur. Stand. (U.S.), 83, No. 6, 529-537 (Nov.-Dec. 1978).

[3] Kilday, M. V., J. Res. Nat. Bur. Stand. (U.S.), 83, No. 6, 539-546 (Nov.-Dec. 1978).

[4] Izatt, R. M., Christensen, J. J., and Rytting, J. H., Chem. Rev. 71, 439-481 (1971).

[5] Scruggs, R. L., Achter, E. K., and Ross, P. D., Biopolymers 11, 1961-1972 (1972).

[6] Nat. Bur. Stand. (U.S.) Spec. Publ. 330, 1977 edition, pg. 11, 41 pages (1977).

[7] Larsen, J. W., and Magid, L. J., J. Phys. Chem. 78, 834-839 (1974).

[8] Gilpin, V., and McCrone, W. C., Anal. Chem. 22, 368 (1950).

[9] Falk, M., Can. J. Chem. 43, 314-318 (1965).

[10] Committee on Specifications and Criteria for Biochemical Compounds, "Specifications and Criteria for Biochemical Compounds," National Academy of Sciences, Washington, DC (1972).

[11] Biltonen, R. L., Department of Pharmacology, University of Virginia School of Medicine, Charlottesville, VA, private communication, July 1977.

[12] Johnson, W. H., J. Res. Nat. Bur. Stand. (U.S.) 79A, (Phys. and Chem.) 425-429 (1975).

[13] Nabavian, M., Sabbah, R., Chastel, R., and Laffitte, M., J. Chim. Phys., Phys. Chim. Biol. 74, 115-126 (1977).

[14] Prosen, E. J., and Kilday, M. V., J. Res. Nat. Bur. Stand (U.S.) 77A (Phys. and Chem.) No. 2, 179-203 (1973).

[15] Commission on Atomic Weights, Pure and Applied Chem. 47, 75-95 (1976). 